\title{
Asp295 Stabilizes the Active-Site Loop Structure of Pyruvate Dehydrogenase, Facilitating Phosphorylation of Ser292 by Pyruvate Dehydrogenase-Kinase
}

\author{
Tripty A. Hirani, 1, 2 Alejandro Tovar-Méndez,, 2 Ján A. Miernyk, 1, 2,3 \\ and Douglas D. Randall ${ }^{1,2}$ \\ ${ }^{1}$ Department of Biochemistry, University of Missouri, Columbia, MO 65211, USA \\ ${ }^{2}$ Interdisciplinary Plant Group, University of Missouri, Columbia, MO 65211, USA \\ ${ }^{3}$ Plant Genetics Research Unit, USDA, Agricultural Research Service, Columbia, MO 65211, USA
}

Correspondence should be addressed to Ján A. Miernyk, miernykj@missouri.edu

Received 23 September 2010; Accepted 5 November 2010

Academic Editor: Heung Chin Cheng

Copyright ( $) 2011$ Tripty A. Hirani et al. This is an open access article distributed under the Creative Commons Attribution License, which permits unrestricted use, distribution, and reproduction in any medium, provided the original work is properly cited.

\begin{abstract}
We have developed an in vitro system for detailed analysis of reversible phosphorylation of the plant mitochondrial pyruvate dehydrogenase complex, comprising recombinant Arabidopsis thaliana $\alpha 2 \beta 2$-heterotetrameric pyruvate dehydrogenase (E1) plus A. thaliana E1-kinase (AtPDK). Upon addition of MgATP, Ser292, which is located within the active-site loop structure of E1 $\alpha$, is phosphorylated. In addition to Ser292, Asp295 and Gly297 are highly conserved in the E1 $\alpha$ active-site loop sequences. Mutation of Asp295 to Ala, Asn, or Leu greatly reduced phosphorylation of Ser292, while mutation of Gly297 had relatively little effect. Quantitative two-hybrid analysis was used to show that mutation of Asp295 did not substantially affect binding of AtPDK to E1 $\alpha$. When using pyruvate as a variable substrate, the Asp295 mutant proteins had modest changes in $k_{\text {cat }}, K_{m}$, and $k_{\text {cat }} / K_{m}$ values. Therefore, we propose that Asp295 plays an important role in stabilizing the active-site loop structure, facilitating transfer of the $\gamma$-phosphate from ATP to the Ser residue at regulatory site one of E1 $\alpha$.
\end{abstract}

\section{Introduction}

The $\alpha$-ketoacid dehydrogenase complexes comprise a unique family of large multienzyme structures, including the pyruvate-, $\alpha$-ketoglutarate-, and branched-chain $\alpha$-ketoacid dehydrogenase complexes and the related glycine decarboxylase complex [1-5]. These complexes have molecular mass values from 4 to $9 \mathrm{MDa}$ and are among the largest non-viral protein assemblies. All family members have multiple copies of three central enzymes: E1, an $\alpha$-ketoacid decarboxylase/dehydrogenase; E2, a dihydrolipoyl acyltransferase; E3, a dihydrolipoyl dehydrogenase. The overall reaction converts the $\alpha$-ketoacid, $\mathrm{NAD}^{+}$, and reduced coenzyme A to $\mathrm{CO}_{2}$, $\mathrm{NADH}$, and an acyl-CoA. The complexes are defined by their $\alpha$-ketoacid specificity

In prokaryotic cells the $\alpha$-ketoacid dehydrogenase complexes are localized in the cytoplasm, while in eukaryotic cells they are within the mitochondrial matrix. Plant cells have a second form of the pyruvate dehydrogenase complex (PDC) which is localized within the plastid stroma $[1,2]$. In addition to subcellular compartmentation, the activities of all of the complexes are regulated by product inhibition. The branched-chain $\alpha$-ketoacid dehydrogenase complexes (BCKDCs) and mitochondrial PDCs are additionally regulated by reversible phosphorylation, mediated by intrinsic E1-kinases $[1-3,6]$ and P-E1-phosphatases $[6,7]$.

The PDC E1 $\alpha$ active-site loop includes two (sites 1 and 2) of the three phosphorylation sites present in mammalian PDC (Figure 1). Plant PDC E1 $\alpha$ sequences include a conserved Ser residue corresponding to mammalian phosphorylation site 1 and a Ser residue one position upstream of site 2 . The Asp295 residue, conserved in both PDC and BCKDC E1 $\alpha$ subunits, is located three residues from phosphorylation site 1 . The results from studies using peptide substrates 


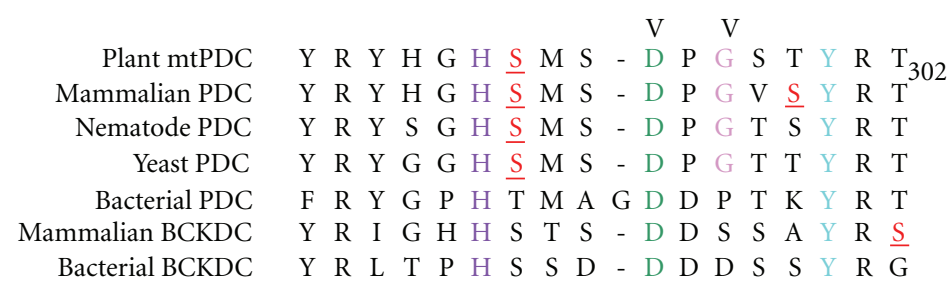

(a)

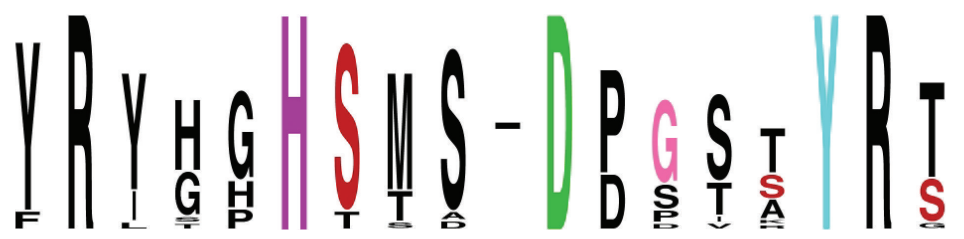

(b)
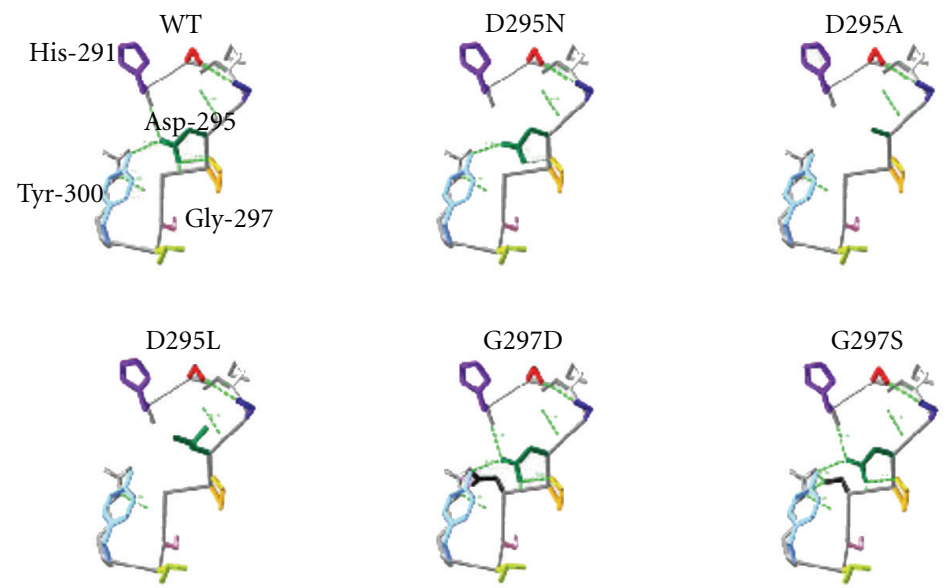

(c)

FIgURE 1: Molecular modeling and in silico mutagenesis of the active-site loop of AtPDC E1 $\alpha$. (a) Alignment of residues in the activesite loop of $\alpha$-ketoacid dehydrogenase E1 $\alpha$ sequences. Numbering is based upon the A. thaliana PDC E1 $\alpha$ sequence. The plant mtPDC sequence is identical in Pisum sativum, A. thaliana, Glycine max, Lycopersicon esculentum, Solanum tuberosum, Beta vulgaris, Nicotiana tabacum, Populus hybrida, Lotus corniculatus, Medicago truncatula, Zea mays, and Oryza sativum. The mammalian PDC sequence is identical in Rattus norvegicus, Mus musculus, and Homo sapiens. The nematode PDC sequence is identical in Ascaris suum and Caenorhabditis elegans. The yeast PDC sequence is identical in Saccharomyces cerevisiae, Schizosaccharomyces pombe, and Kluyveromyces lactis. Bacterial PDC sequences are identical from Bacillus subtilis and Bacillus stearothermophilus. The mammalian BCKDC sequence is identical in H. sapiens, M. musculus, and Ovis aries. The bacterial BCKDC sequence is from B. subtilis. The carats denote the Asp and Gly residues targeted in this study. The red underlined Ser residues correspond to mammalian pyruvate dehydrogenase phosphorylation sites 1 and 2 and mammalian BCKDC phosphorylation site 2. (b) The consensus active-site loop primary sequence presented as output from the WebLogo program [9]. (c) Carbon-alpha trace from modeling of residues His-291 to Arg-301 in the active site loop of AtE1 $\alpha$. The same colors have been used for each residue in all panels. Hydrogen bonds are indicated with green dashed lines. Traces were built using Swiss-PDB viewer (version 3.7).

indicate that this residue is important for phosphorylation of E1 at site 1, and it has been proposed to be involved with PDK binding [8]. The Gly297 residue is conserved only in forms of PDC E1 that are phosphorylated, and there is a corresponding Ser residue in the BCKDC E1 $\alpha$ sequences. This suggests that a small residue in this position is required for an appropriate conformation of the active-site loop for E1 phosphorylation.

Limited proteolysis has been used to probe the reaction mechanism of the dehydrogenase/decarboxylase (E1) component of mammalian $\alpha$-ketoacid dehydrogenase complexes [10-13]. In all cases, loss of catalytic activity resulted from cleavage of the $\mathrm{E} 1 \alpha$ subunit, while $\mathrm{E} 1 \beta$ remained unaffected. Limited proteolysis of Bacillus stearothermophilus PDC revealed that it is the surface loop of the E1 $\alpha$ subunit structure that is susceptible to cleavage [14]. In the crystal structures of the BCKDC E1 from Pseudomonas putida [15] and Homo sapiens [16] and of the PDC E1 from H. sapiens [17], it is clear that this loop lies in the funnel-shaped active site formed by the $\mathrm{E} 1 \alpha$ and $\mathrm{E} 1 \beta$ subunits and is 20 $25 \AA$ from the binding site of the thiamine pyrophosphate cofactor. The primary sequence of the active-site loop is conserved among plant and mammalian PDC E1 proteins, and, while sequence conservation with BCKDC is less, 
both loops have a similar structure $[16,17]$ suggesting that the individual residues (conserved or variable) perform the same biochemical function.

Site-directed mutagenesis of the active-site loop from mammalian PDC E1 $\alpha$ highlighted the roles of Arg267 in binding the carboxyl group of pyruvate and Asp276, Tyr281, and Arg282 in both decarboxylation of pyruvate and the subsequent reductive acetylation of the lipoyl domains of E2 [18]. In addition, Ala scanning mutagenesis of the active-site loop of RnBCKDC E1 $\alpha$ provided evidence that Arg288, His292, and Asp296 are also involved in catalysis $[19,20]$. Moreover, the clinically deleterious H263L and R273C mutations of HsPDC E1 $\alpha$ result in greatly reduced PDC activity [21, 22]. These residues correspond to Arg287, His291, Asp295, Tyr300, and Arg301 of the Arabidopsis thaliana PDC E1 $\alpha$ (AtPDC E1 $\alpha$ ) sequence (Figure 1).

To better understand the catalytic mechanisms and regulatory properties of the plant mitochondrial PDC, it was necessary to develop a method to produce the recombinant enzyme that is both soluble and correctly assembled into the $\alpha 2 \beta 2$ heterotetramer. Previous attempts to use Bacillus subtilis [23] and Pichia pastoris [24] expression systems were plagued by problems with protein solubility and stability and codon usage bias. Herein, we describe a two-plasmid approach for expression of catalytically active heterotetrameric AtPDC E1 in Escherichia coli. Using a minimum in vitro assay system of recombinant AtPDC E1 and AtPDK, we have begun detailed analyses of the reversible phosphorylation of E1. We verified that the Ser residue corresponding to mammalian site 1 is a site of regulatory phosphorylation. Additionally, we targeted Asp295 and Gly297, residues conserved in the active-site loop but not previously tested for their contribution(s) to the catalytic activity of E1, and role(s) in phosphorylationsite recognition by PDK. Our results suggest that Asp295, but not Gly297, is involved in both E1 catalysis and phosphorylation.

\section{Experimental Procedures}

2.1. Plasmid Construction. A two-plasmid system was used for expression of AtPDC E1. Primers DDR321 and 322 (see Table S1 in Supplementary Material available online at doi:10.4061/2011/939068) were used to amplify the AtPDC E1 $\alpha$ reading frame [25]. The DDR321 primer includes a NdeI site, a $\mathrm{H}_{6}$-affinity tag, and starts with $\mathrm{S} 18$ of $\mathrm{E} 1 \alpha$, the first residue after the $\mathrm{N}$-terminal mitochondrial targeting sequence. The PCR product was cut with NdeI and XhoI, then ligated with similarly digested pT7-7 [26], yielding pDDR-E1 $\alpha$.

Similarly, primers DDR323 and 324 (Table S1) were used to amplify the AtPDC E1 $\beta$ reading frame [27]. The DDR323 primer includes a NcoI site, the FLAG epitope (DYKDDDDK) [28], and starts with $\mathrm{A} 30$ of $\mathrm{E} 1 \beta$, the first residue after the $\mathrm{N}$-terminal mitochondrial targeting sequence. The PCR product was digested with NcoI and HinDIII, then ligated with similarly digested pET28 (Novagen, Madison, WI, USA), yielding pDDR-E1 $\beta$.
2.2. Protein Expression and Purification. The E. coli BL21 (DE3) host cells (Novagen, Madison, WI, USA) were sequentially transformed to express the GroE chaperonins [29], AtPDC E1 $\beta$-pET28, and finally AtPDC E1 $\alpha$-pT7-7. Protein expression was induced by adding IPTG to a final concentration of $0.1 \mathrm{mM}$. Individual transformants were screened for high-level expression of soluble AtPDC E1. Cell growth, lysis, and affinity purification of recombinant AtPDC E1 and AtPDK are described elsewhere [30].

2.3. Size-Exclusion Chromatography. Assembly of heterotetrameric AtPDC E1 was determined by size-exclusion chromatography. A Superose 12 column (Amersham Pharmacia Biotech, Piscataway, NJ, USA) was equilibrated with $50 \mathrm{mM}$ TES- $\mathrm{NaOH}, \mathrm{pH}$ 7.4, containing $50 \mathrm{mM} \mathrm{NaCl}, 0.1 \mathrm{mM}$ TPP, and $0.2 \mathrm{mM} \mathrm{MgCl}$. Column fractions were analyzed by SDS-PAGE, and the AtPDC E1 subunits were detected by immunoblotting [31]. The E1 $\alpha$ monoclonal antibodies have been previously described [32]. Anti-FLAG antibodies were from the Sigma Chemical Co. (St. Louis, MO, USA).

2.4. Site-Directed Mutagenesis. Site-directed mutagenesis of AtPDC E1 $\alpha$ was accomplished using the QuikChange kit from Stratagene (La Jolla, CA, USA). The S292D/S298A double mutant was constructed by preparing the S298A mutant first, then using it as the template for a second round of mutagenesis. The mutagenic primer pairs were DDR162 and DDR163 (S292A), DDR431 and DDR432 (S298A), DDR425 and DDR426 (S292D), DDR444 and DDR445 (G297S), DDR446 and DDR447 (G297D), DDR448 and DDR449 (D295N), DDR450 and DDR451 (D295A), and DDR452 and DDR453 (D295L) (Table S1). All mutations were verified by DNA sequencing.

2.5. Far-UV Circular Dichroism Spectroscopy. The various expressed E1 proteins were examined by far-UV CD spectroscopy using an AVIV Model 202 spectrometer (Piscataway, NJ, USA) to determine if the site mutations introduced any significant perturbation in AtPDC E1 structure. Samples were analyzed at room temperature using a $0.1 \mathrm{~cm}$ path-length cuvette, and spectra were recorded from 190 to $300 \mathrm{~nm}$ at $1 \mathrm{~nm}$ intervals with a bandwidth of $1 \mathrm{~nm}$. For each analysis, $200 \mu \mathrm{L}$ of purified protein in $20 \mathrm{mM}$ $\mathrm{KH}_{2} \mathrm{PO}_{4} / \mathrm{K}_{2} \mathrm{HPO}_{4}$ (pH 7.4) at a concentration of $100-$ $200 \mu \mathrm{g} / \mathrm{mL}$ was used.

2.6. Phosphorylation of AtPDCE1. Phosphorylation was determined by measuring the incorporation of $\left[{ }^{32} \mathrm{P}\right]$ from $\left[\gamma^{-32} \mathrm{P}\right]$ ATP $(6000 \mathrm{Ci} / \mathrm{mmole}$, Perkin-Elmer, Boston, MA, USA) into AtPDC E1. Recombinant E1 ( $1 \mu \mathrm{g})$ was mixed with recombinant AtPDK $(0.25 \mu \mathrm{g})$ and kept for $30 \mathrm{~min}$ on ice. Reactions were conducted at $30^{\circ} \mathrm{C}$ in $20 \mathrm{mM}$ TES- $\mathrm{NaOH}$, $\mathrm{pH}$ 7.4, containing $5 \mathrm{mM} \mathrm{MgCl}_{2}, 50 \mathrm{mM} \mathrm{KCl}$, and $0.2 \mathrm{mM}$ total ATP. Reactions were terminated after $90 \mathrm{~min}$ by adding $1 / 5$ volume of $5 x$ SDS-PAGE sample buffer ( $15 \%$ (w/v) SDS, $15 \%(\mathrm{v} / \mathrm{v}) 2$-mercaptoethanol, 50\% (v/v) glycerol). Proteins were resolved by SDS-PAGE, electroblotted to nitrocellulose, and examined by autoradiography. The incorporation of 
radiolabel into AtPDC E1 was quantified by liquidscintillation spectrometry of the bands excised from Ponceau $S$ stained membranes.

2.7. Peptide Mass Mapping of Phosphorylated E1 $\alpha$ by MatrixAssisted Laser Desorption/Ionization Time-of-Flight Mass Spectrometry. The AtPDC E1 $\alpha$ S298A mutant was phosphorylated by AtPDK using nonradioactive ATP. After SDSPAGE, the AtPDC E1 $\alpha$ band was excised and subjected to in-gel tryptic digestion. Desalted tryptic peptides in acetonitrile/water/88\% formic acid (700/290/10, V/V/V) were applied to a $96 \times 2$ hydrophobic stainless steel target and topped with an equal volume of a $10-\mathrm{mg} / \mathrm{mL}$ solution of alpha-cyano-4-hydroxycinnamic acid (Fluka, St. Louis, $\mathrm{MO}, \mathrm{USA}$ ) in acetonitrile/water $/ 10 \%$ trifluoroacetic acid $(600 / 370 / 30, V / V / V)$. The sample and matrix were allowed to cocrystallize under ambient conditions. Matrix-assisted laser desorption/ionization time-of-flight (MALDI TOF) mass spectrometry was performed with an Applied Biosystems Voyager DEPro instrument equipped with a $20-\mathrm{Hz} 337-$ $\mathrm{nm}$ nitrogen laser (Applied Biosystems, Inc., Foster City, CA, USA). Negative ion spectra were acquired in the linear delayed extraction mode under optimized conditions using close-external calibration based on a commercial mixture of peptides (Applied Biosystems).

2.8. Tandem MS Analysis of Tryptic Peptides. The desalted tryptic peptides from the phosphorylated AtPDCE1 $\alpha$ S298A mutant protein were analyzed by nanospray quadrupole time-of-flight mass spectrometry (Q-TOF MS) using an Applied Biosystems/MDS Sciex (Foster City, CA, USA) QStar/Pulsar instrument fitted with a nanospray source (Proxeon Biosystems, Odense, Denmark). A stable spray was achieved at $750 \mathrm{~V}$ in the presence of nitrogen curtain gas for sample dissolved in acetonitrile/water $/ 88 \%$ formic acid (500/490/10, V/V/V). Positive ion spectra were acquired in the profile MCA mode at a pulser frequency of $6.99 \mathrm{kHz}$. Collision-induced dissociation spectra (MS/MS) were acquired for peptides selected by the first quadrupole at low resolution (3-5 amu window) and fragmented in the collision quadrupole at appropriate nitrogen collision gas pressures and collision energy settings. Fragmented ions were assigned nomenclature according to [33].

2.9. Measurement of Catalytic Activity. The catalytic activity of WT AtPDC E1 and site-directed mutants was determined by assaying the decarboxylation of $\left[1-{ }^{14} \mathrm{C}\right]$ pyruvate $(20 \mathrm{mCi} / \mathrm{mmol}$, Perkin-Elmer, Boston, MA, USA) in the presence of $1.0 \mathrm{mM} \mathrm{K} \mathrm{K}_{3} \mathrm{Fe}(\mathrm{CN})_{6}$ as the electron acceptor [34]. Reactions were preincubated for $2 \mathrm{~min}$ at $30^{\circ} \mathrm{C}$ before adding $1 \mathrm{mM}\left[1-{ }^{14} \mathrm{C}\right]$ pyruvate and $1 \mu \mathrm{g}$ AtPDC E1. One unit of enzyme activity is $1 \mu \mathrm{mol}$ of $\mathrm{CO}_{2}$ released per min at $30^{\circ} \mathrm{C}$. All of the data presented comprise a minimum of two biological replicates plus three technical replicates.

Kinetic constants were determined by measuring decarboxylation of pyruvate in the presence of $1.8 \mu \mathrm{M} \mathrm{K}_{3} \mathrm{Fe}(\mathrm{CN})_{6}$. The lower concentration of $\mathrm{K}_{3} \mathrm{Fe}(\mathrm{CN})_{6}$ reduced the otherwise high and variable background values to near zero.
A fixed variable concentration of pyruvate ranging from 50 to $900 \mu \mathrm{M}$ was used with $1 \mu \mathrm{g}$ AtPDC E1. Data were fitted to the appropriate equations using the program Origin 7 (OriginLab Corporation, Northampton, MA, USA). The $K_{m}$ and $k_{\text {cat }}$ values were determined from initial-rate measurements and fit to the equation $v=\left(k_{\text {cat }} \times \mathrm{S}\right) /\left(K_{m}+\mathrm{S}\right)$, where $S=$ substrate concentration.

2.10. Bacterial Two-Hybrid Analysis. Interactions between AtPDK and AtPDC E1 $\alpha$ were analyzed using the bacterial two-hybrid (B2H) system (BacterioMatch I, Stratagene, La Jolla, CA, USA). Primers DDR471 and DDR472 were used to amplify WT AtPDK [30], while primers DDR473 and DDR474 were used to amplify both WT and mutant forms of E1 $\alpha$. The AtPDK sequence was cloned into pBT, and the AtE $1 \alpha$ constructs were cloned into pTRG. Pairs of constructs were used to cotransform the E. coli BacterioMatch I reporter strain. Selection was on Luria-Bertani agar containing $250 \mu \mathrm{g} / \mathrm{mL}$ carbenicillin, $12.5 \mu \mathrm{g} / \mathrm{mL}$ tetracycline, $34 \mu \mathrm{g} / \mathrm{mL}$ chloramphenicol, and $50 \mu \mathrm{g} / \mathrm{mL}$ kanamycin. Cells selected by antibiotic screening were additionally screened on LB plates containing $80 \mu \mathrm{g} / \mathrm{mL} \mathrm{X-gal} \mathrm{plus}$ $0.2 \mathrm{mM} \beta$-galactosidase inhibitor (to inhibit endogenous $\beta$-galactosidase). Interactions between PDK and the E1 $\alpha$ mutants were quantified by measuring $\beta$-galactosidase activity $[35,36]$. The microplate spectrophotometric assay uses o-nitrophenyl- $\beta$-D-galactoside as the substrate.

\section{Results}

3.1. In Silico Analysis of the E1 $\alpha$ Active-Site Loop. The activesite loop is a structural feature critical for both catalysis by E1 and phosphorylation of E1 by PDK. Overall, there is $50 \%$ sequence identity among the amino acid residues that comprise the active-site loop of diverse members of the $\alpha$-ketoacid dehydrogenase family (Figure 1(a)). Two of the conserved residues were targeted in this study, Asp295 and Gly297. Located three residues C-terminal of phosphorylation site 1 (Ser292), Asp295 is the only acidic residue in proximity to this phosphorylation site. It is entirely conserved among $\alpha$-ketoacid dehydrogenase sequences.

The primary sequence of AtPDC E1 $\alpha$ was threaded through the crystal structure of $\mathrm{HsE} 1 \alpha$ [17]. The resulting model indicates that Asp295 protrudes into the loop and can interact with His291 and Tyr300 (Figure 1(b)). The results from in silico mutagenesis of Asp295 indicate that these interactions would be disrupted if the hydrophilic side chain was replaced with an uncharged polar residue, that is, D295N. In the D295A and D295L mutants, interactions with His291 and Tyr300 would be completely abolished. The active-site loop is a highly charged region. If Asp295 plays a structural role in maintaining the structure of the loop, the mutations would disrupt substrate binding and/or interaction with AtPDK.

Of the five residues proximal to Ser292, Gly297 is conserved in eukaryotic PDC sequences, but not in those of the BCKDC. Since Gly297 is not in the immediate vicinity of Ser292, mutation would not be expected to directly affect 
phosphorylation of E1 but might still be involved with either presentation of the phosphorylation site to the kinase-active site or catalysis. The corresponding position in BCKDC contains a Ser residue suggesting that a small residue at this position may be sufficient for the structural conformation of the active-site loop. In silico, the G297D and G297S mutants do not affect the N-terminal interactions of Asp295 but induce an additional interaction with Arg301 (Figure 1(c)).

3.2. Expression of Recombinant AtPDCE1. A two-plasmid approach was employed for expressing high yields of correctly assembled and fully active $\alpha_{2} \beta_{2}$ heterotetrameric AtPDC E1 in E. coli. Expression of only the AtPDC E1 $\alpha$ or E1 $\beta$ subunits individually invariably yielded only insoluble subunits (Figure 2(a)), while coexpression of the $\alpha$ - and $\beta$ subunits resulted in a substantial amount of soluble protein (Figure 2(b)). Immobilized metal affinity chromatography was used to purify recombinant AtPDC E1; analysis of the purification steps by SDS-PAGE is shown in Figures 2 (b) and 2(c). The co-occurrence of $\alpha$ - and $\beta$-subunits was verified by immunoblotting (Figure $2(\mathrm{~d})$ ). Based upon visual examination of Coomassie Blue-stained SDS gels, it was estimated that final preparations of AtPDC E1 were 95\% pure.

To confirm the assembly of heterotetrameric AtPDC E1, the purified protein was subject to size-exclusion chromatography. Most recombinant protein eluted from the Sepharose 12 column at a position corresponding to an $M_{r}$ value of 160,000, which is what would be expected for an $\alpha_{2} \beta_{2}$ heterotetramer. The far-UV CD spectra of the E1 proteins indicated no significant changes in secondary structure between WT AtPDC E1 and any of the site-directed mutants (data not presented).

3.3. Catalytic Activity of Recombinant AtPDC E1. The specific activity values for the WT and mutant forms of AtPDC E1 are shown in Table 1. The activity of the S292A mutant was reduced by $25 \%$, while there was no change in the activity of the S298A mutant. In contrast, the activities of the S292D and S292D/S298A mutants were reduced by $>90 \%$. The activities of the G297D and G297S mutants were reduced by 25 to $30 \%$, while those of the D295A and D295N mutants were reduced by $60 \%$. The D295L mutant protein was essentially inactive ( $1 \%$ residual activity).

The kinetic parameters of WT and the mutants, using pyruvate as the variable substrate, are shown in Table 2. The $k_{\text {cat }}$ values for the D295A and D295N mutants were reduced $\sim 70 \%$. The $K_{m}$ pyruvate values for the D295A and D295N mutants were increased 4- to 6-fold compared with WT AtE1. The $k_{\text {cat }}$ value for the G297D mutant was reduced by $50 \%$ without any change in $K_{m}$ pyruvate. In these mutants, the catalytic efficiency $\left(k_{\mathrm{cat}} / K_{m}\right)$ was reduced by 3.5 to 35 fold, reduction that, although significant, is modest for the changes expected on mutation of residues directly involved in substrate binding and/or catalysis.

3.4. Phosphorylation of AtPDC E1 In Vitro. Incubation of WT AtPDC E1 with recombinant AtPDK using $200 \mu \mathrm{M}$
TABle 1: The specific activities of WT and mutant AtPDC E1 proteins were determined by assaying the decarboxylation of $\left[1-{ }^{14} \mathrm{C}\right]$ pyruvate in the presence of $1.0 \mathrm{mM} \mathrm{K}{ }_{3} \mathrm{Fe}(\mathrm{CN})_{6}$ as the electron acceptor.

\begin{tabular}{lcc}
\hline Enzyme & $\begin{array}{c}\text { Specific activity } \\
\text { (units/mg) }\end{array}$ & $\%$ \\
\hline WT AtPDCE1 & $0.32 \pm 0.01$ & 100 \\
S292A & $0.24 \pm 0.06$ & 74 \\
S298A & $0.31 \pm 0.02$ & 97 \\
S292D & $0.02 \pm 0.03$ & 6 \\
S292D/S298A & $0.03 \pm 0.03$ & 9 \\
D295A & $0.12 \pm 0.01$ & 37 \\
D295N & $0.12 \pm 0.01$ & 37 \\
D295L & 0.003 & 1 \\
G297D & $0.24 \pm 0.03$ & 75 \\
G297S & $0.22 \pm 0.04$ & 68 \\
\hline
\end{tabular}

TABLe 2: Kinetic parameters of WT AtPDC E1 and site-directed mutants. Activities were determined by assaying decarboxylation of $\left[1-{ }^{14} \mathrm{C}\right]$ pyruvate in the presence of $1.8 \mu \mathrm{M} \mathrm{K}_{3} \mathrm{Fe}(\mathrm{CN})_{6}$.

\begin{tabular}{lccc}
\hline Enzyme & $\begin{array}{c}K_{m} \text { pyruvate } \\
(\mu \mathrm{M})\end{array}$ & $k_{\mathrm{cat}}\left(\mathrm{s}^{-1}\right)$ & $\begin{array}{c}k_{\mathrm{cat}} / K_{m} \\
\left(\mu \mathrm{M}^{-1} \mathrm{~s}^{-1}\right)\end{array}$ \\
\hline WTAtE1 & $45 \pm 18$ & $159 \pm 14$ & 3.5 \\
D295A & $178 \pm 108$ & $52 \pm 12$ & 0.3 \\
D295N & $257 \pm 144$ & $38 \pm 10$ & 0.1 \\
G297D & $66 \pm 24$ & $70 \pm 7$ & 1.0 \\
\hline
\end{tabular}

$\left[\gamma^{32} \mathrm{P}\right]$ ATP resulted in the phosphorylation of a single polypeptide species (Figure 3(a), lane 1). To analyze regulatory phosphorylation site 1 of AtPDC E1, three different mutants were constructed. The S292A mutant targets the conserved phosphorylation site 1, while the S298A mutant targets potential phosphorylation of the putative site 2 . The S292D/S298A double mutant was constructed to mimic phosphorylation of AtPDC E1 $\alpha$ Ser292 in the absence of a residue that could be phosphorylated at site 2 .

Incubation of the mutant proteins with recombinant AtPDK plus $200 \mu \mathrm{M}\left[\gamma^{-32} \mathrm{P}\right]$ ATP resulted in phosphorylation of a single polypeptide species for the S298A mutant (Figure 3, lane 3). There were only trace amounts of phosphate incorporated into the S292A mutant (2\% of WT) and into the S292D/S298A double mutant (1\% of WT).

\subsection{Analysis of the Phosphorylated AtPDC E1 $\alpha$ S298A Mutant} by Mass Spectrometry. To verify that Ser292 was the site phosphorylated in vitro, the S298A mutant was phosphorylated with recombinant AtPDK plus unlabeled ATP, then subjected to in-gel tryptic digestion. The MALDI-TOF MS analysis of the tryptic peptides revealed an ion at $\mathrm{M}$ $\mathrm{H}^{-}$1656.9 Da, which corresponds to the phosphopeptide Tyr286-Arg301 (Figure 4(a)). This was the only peptide detected by negative ion nanospray QqTOF precursor ion analysis that yielded the diagnostic fragment ion for 


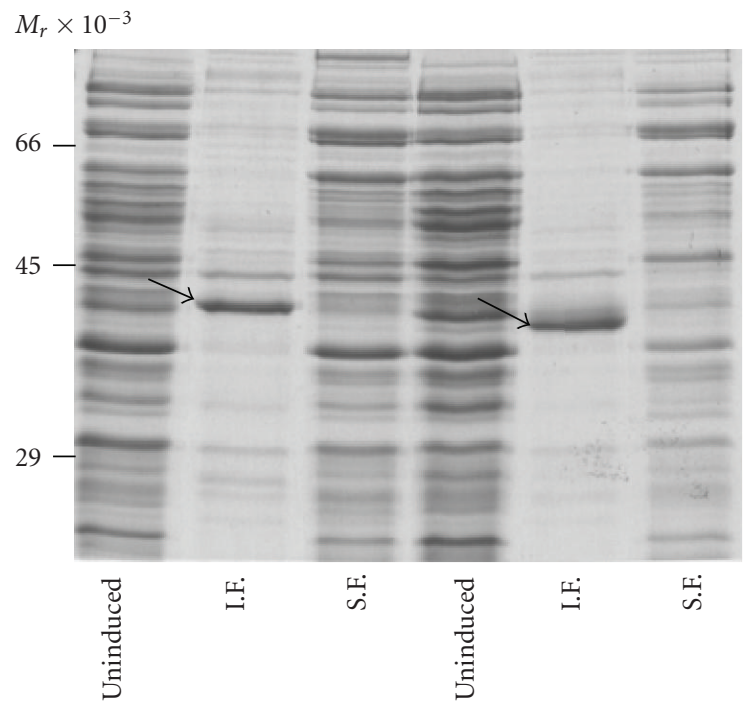

(a)

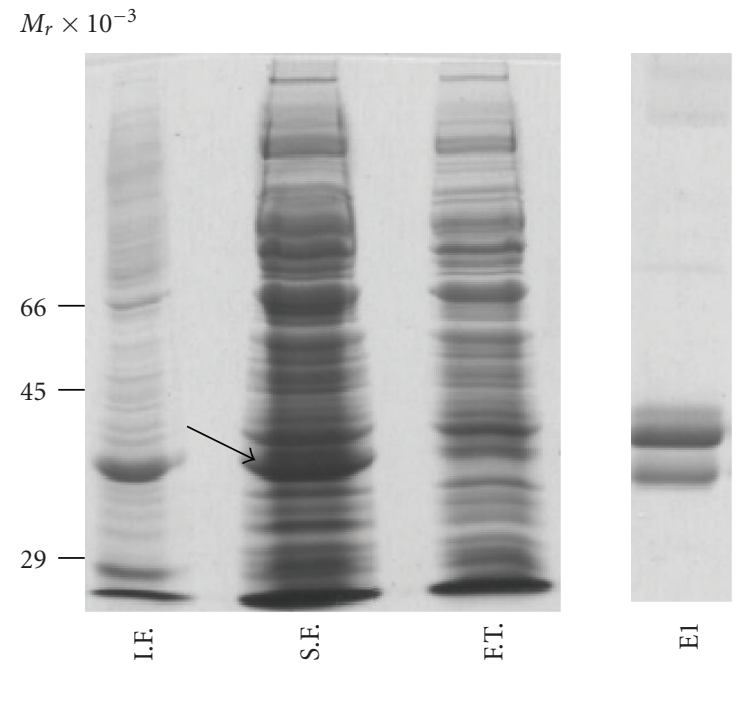

(b)

(c)

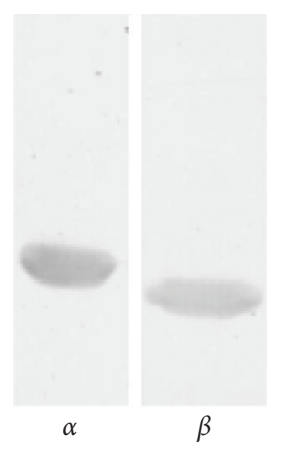

(d)

FIGURE 2: Expression and purification of A. thaliana pyruvate dehydrogenase. (a) Bacterial expression of AtPDC E1 $\alpha$ and E1 $\beta$. An SDS gel of total proteins from uninduced E. coli BL21 (DE3) cells containing pT7-7:AtE1 $\alpha$; insoluble (I.F.) and soluble (S.F.) fractions from induced cells; total proteins from uninduced cells containing pET28:AtE1 $\beta$; insoluble and soluble fractions from induced cells. The positions of AtPDC E1 $\alpha$ and E1 $\beta$ are indicated by arrows. (b) An SDS gel of a typical 2-plasmid AtPDC E1 $\alpha$ plus $\beta$ coexpression and purification profile using the HiTrap chelating column charged with $0.1 \mathrm{M} \mathrm{NiSO}_{4}$; insoluble fraction, soluble fraction, flow through (F.T.). The position of AtPDC E1 $\beta$ in the soluble fraction is indicated by an arrow. (c) A Coomassie-stained SDS gel of AtPDC E1 after immobilized metal affinity chromatography. (d) Immunoblot analysis of AtPDC E1. The E1 $\alpha$ subunit was detected with monoclonal anti-E1 $\alpha$ antibodies, and the E1 $\beta$ subunit was detected with monoclonal anti-FLAG antibodies. The positions of molecular mass markers are indicated on the left for (a) and (b). All gels (except the Immunoblot) were stained with Coomassie Blue.

phosphopeptides, $78.96 \mathrm{Da}$ (the $\mathrm{PO}_{3}{ }^{-}$ion). The sequence of this peptide was confirmed by positive ion nanospray QqTOF tandem MS analysis of the triple-charge ion at 553.55 Da in the peptide mixture (Figure 4(b)). The assignment of phosphate to Ser292 is supported by the presence of fragment ions $\mathrm{b5}^{+}(662.25 \mathrm{Da}), \mathrm{b6}^{+}(793.23 \mathrm{Da})$, and a complete y-ion series including y $10^{+}(1164.41 \mathrm{Da})$. The most plausible interpretation of these data is that the Tyr286Arg301 tryptic peptide is phosphorylated at Ser292. Tandem MS analyses of the double-charge ion at $829.8 \mathrm{Da}$ and the triple-charge ion for the Met-oxidised form of the peptide at 558.9 $\mathrm{Da}$ provided additional evidence for phosphorylation of Ser292 (data not shown).
3.6. Phosphorylation of the Asp295 and Gly297 Mutants. Comparison of WT and mutant AtPDC E1 proteins incubated with AtPDK for 90 min showed substantial differences in phosphorylation (Figures 5(a) and 5(b)). In comparison with WT E1, phosphorylation of the D295A and D295N mutants was reduced by 92 and $83 \%$, respectively, while phosphorylation of the D295L mutant was abolished ( $\sim 3 \%$ residual phosphorylation) (Figure 5(a)). In contrast, phosphorylation of the G297D and G297S mutants was little affected, being reduced 9 and 13\%, respectively.

The data in Figure 5(c) show a time-dependent increase in phosphorylation of the G297D mutant, similar to that seen 
with the WT protein. In contrast, the low-level phosphorylation in the D295A and D295N mutant proteins did not increase with an increase in time.

3.7. B2H Analysis of Protein Interactions. Interaction between $\mathrm{PDK}$ and $\mathrm{E} 1$ in our reconstituted in vitro system comprises a multistep sequence including recognition, binding, and phosphotransfer. We used the $\mathrm{B} 2 \mathrm{H}$ synthetic genetic system to test the possibility that reduced phosphorylation of the AtPDC E1 $\alpha$ D295A and D295N mutants was due to impaired binding of PDK. In these assays, protein interaction is quantified using the $\beta$-galactosidase reporter. Interactions between AtPDK and the mutant forms of AtPDC E1 $\alpha$ were slightly reduced relative to WT E1 $\alpha$ (Figure 6). It does not appear, however, that these small decreases in protein interaction are adequate to explain the large decreases in phosphorylation (Figure 5).

\section{Discussion}

Two approaches were used previously to express recombinant plant mitochondrial PDC E1. Staphylococcal protein A-based vectors were constructed to direct secretion of the $\mathrm{E} 1 \alpha$ and $\mathrm{E} 1 \beta$ subunits of $P$. sativum pyruvate dehydrogenase from separate strains of $B$. subtilis [23]. A bipartite vector was designed for simultaneous expression of $\mathrm{E} 1 \alpha$ and $\mathrm{E} 1 \beta$ subunits in the cytoplasm of $P$. pastoris, but very low yields were the result of an unfavorable codon-usage bias [24]. While useful for analytical studies of E1 assembly, these systems yielded too little protein for detailed biochemical characterizations.

The envisioned analyses necessitated development of a method for heterologous expression and rapid purification of active, correctly folded and assembled recombinant AtPDC E1. The E. coli coexpression strategy routinely yielded $\sim 8 \mathrm{mg}$ of purified $\mathrm{E} 1$ per $500 \mathrm{~mL}$, and more than $90 \%$ of this was assembled into heterotetramers. Catalytic activity was seemingly not influenced by the N-terminal $\mathrm{His}_{6}$-tag. When individually expressed at high levels neither subunit was soluble, suggesting that correct folding and assembly of large amounts of the heteromeric enzyme require the simultaneous presence of both subunits. Complexity in the folding and assembly pathway was not unexpected based upon previous reports [23, 24, 37, 38] and the reported participation of the GroE chaperonins [39-41].

Recombinant tetrameric AtPDC E1 catalyzed decarboxylation of pyruvate in the presence of high $(1.0 \mathrm{mM})$ and low $(1.8 \mu \mathrm{M})$ concentrations of the artificial electron acceptor $\mathrm{K}_{3} \mathrm{Fe}(\mathrm{CN})_{6}$ (Tables 1 and 2). The specific activity of the recombinant enzyme was $0.32 \mu \mathrm{mol} \mathrm{min}{ }^{-1} \mathrm{mg}^{-1}$ protein in assays containing $1 \mathrm{mM} \mathrm{K}_{3} \mathrm{Fe}(\mathrm{CN})_{6}$. This is $\sim 2$-fold higher than the values reported for recombinant HsPDC E1 [42] or native E. coli E1 [43] under similar assay conditions. The $K_{m}$ pyruvate value for recombinant AtPDC E1 is similar to that of native pea mitochondrial PDC [44] but cannot be compared directly because of differences in assay procedures.

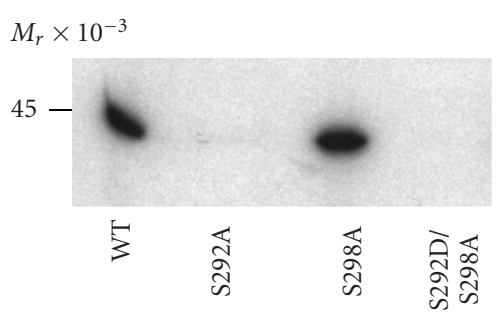

(a)

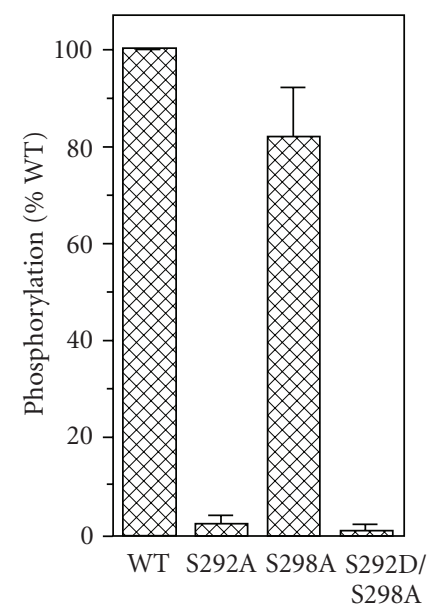

(b)

Figure 3: Phosphorylation of recombinant AtPDC E1 by recombinant AtPDK. (a) Autoradiograph of the in vitro phosphorylation of wild-type (WT) AtE1 $\alpha$, and the S292A and S298A mutants, by recombinant AtPDK. One $\mu \mathrm{g}$ of E1 was incubated with $0.25 \mu \mathrm{g}$ PDK and $200 \mu \mathrm{M}\left[\gamma_{-}{ }^{32} \mathrm{P}\right] \mathrm{ATP}$, at $30^{\circ} \mathrm{C}$ for $90 \mathrm{~min}$. When the film was developed after $3 \mathrm{~h}$, phosphorylation of the WT and the S298A proteins was visible, while no phosphorylation was observed for the S292A and the double mutants. Furthermore, no phosphorylation of the S292A or double mutants was observed when the same film was developed after $16 \mathrm{~h}$. (b) Phosphorylation of the mutant proteins relative to WT. The $100 \%$ phosphorylation value of WT was $1.0 \pm 0.04 \mu \mathrm{mol}^{32} \mathrm{P}$ mol AtPDC E1 ${ }^{-1}$. Data are the mean values from at least three separate determinations \pm SEM.

There are currently no literature $k_{\text {cat }}$ values for recombinant E1 proteins.

The catalytic activity of the AtPDC E1 S292A mutant was reduced by $26 \%$ (Table 1 ), which is essentially identical to the effect previously reported for HsPDC E1 [42]. The activity of the AtPDC E1 S292D/S298A double mutant was reduced by $90 \%$ (Table 1). Replacement of the HsPDC E1 site 1 Ser residue with the P-Ser mimic Glu reduced decarboxylase activity but abolished PDC activity. This result agrees with the previous observations that phosphorylation has a more pronounced effect on reductive acetylation than on substrate binding $[43,45]$.

Recombinant AtPDC E1 was efficiently phosphorylated in vitro by AtPDK. One mole of phosphate was incorporated per mol of subunit dimer. (Figure 3). The slight ${ }^{32} \mathrm{P}$ incorporation on the S292A mutant and the unaffected phosphorylation level of the S298A mutant catalyzed by 


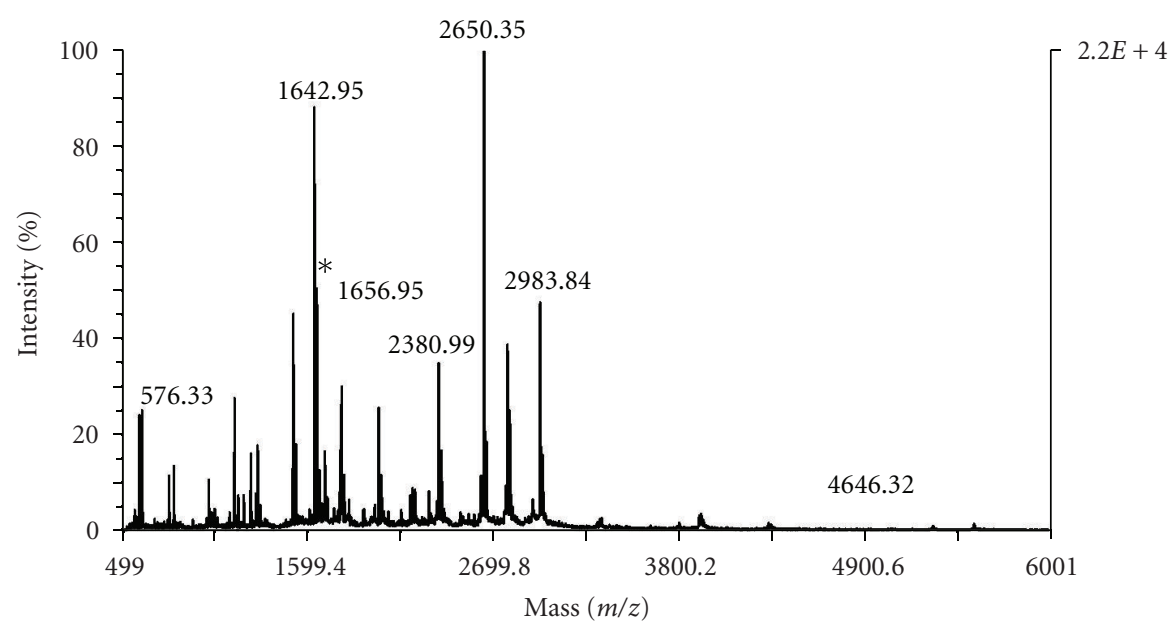

(a)

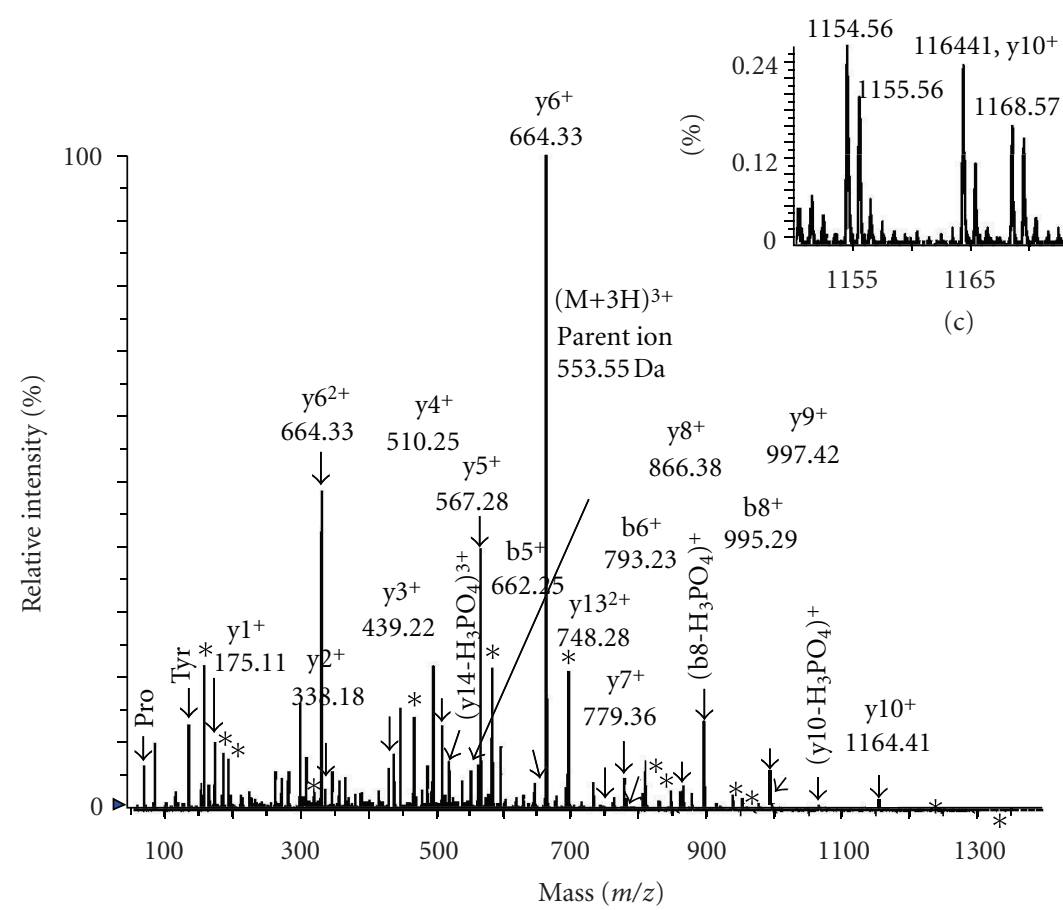

(b)

FIGURE 4: Analysis of the AtPDC E1 $\alpha$ S298A mutant phosphorylation site by mass spectrometry. (a) MALDI-TOF MS analysis of tryptic peptides from the AtPDC E1 $\alpha$ S298A mutant. The $1656.9 \mathrm{~m} / z$ ion corresponds to the phosphopeptide Tyr286 to Arg301. (b) Fragmentation of the $m / z 1656.9$ peptide by nanoelectrospray tandem MS. Fragment ion spectrum from the triple-charge molecular ion at $m / z 553.55$. The ions $\mathrm{b}^{+}$(662.25), $\mathrm{b}^{+}$(793.23), and y10 $(1164.41)$ indicate P-Ser292. The asterisks mark the fragment ions from the S298A-methylated peptide that was also present in the parent ion envelope at $(\mathrm{M}+3 \mathrm{H})^{3+}$ of $553.95 \mathrm{Da}$. (c) Expanded spectrum of the y10 $0^{+}$ion.

AtPDK suggested that only Ser292 is phosphorylated in our assay condition (Figure 3). Analysis of the S298A mutant by QqTOF tandem MS verified phosphorylation of only Ser292 (Figure 4). Our finding that only site 1 is phosphorylated with the reconstituted minimum $A$. thaliana system is in agreement with results obtained using the recombinant human proteins [46] and validate use of the plant system for further mechanistic studies.
There is no reason to believe that the enzymatic mechanism is somehow different in the absence/presence of E2. While the rate of E1 phosphorylation by $\mathrm{PDK}$ is higher in the presence of E2 (and higher yet with PDC) [47], this stimulation is due to a direct kinetic effect; that is, ADP disassociates faster from PDK when it is bound to E2 [48]. Our results are consistent with a previous study, using two-dimensional separation of phosphoproteins 


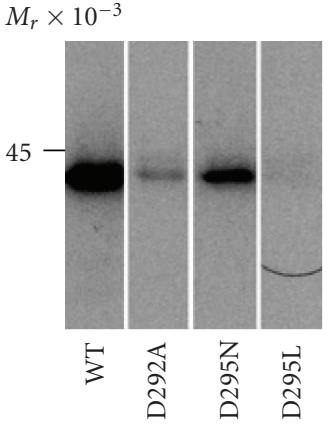

(i)

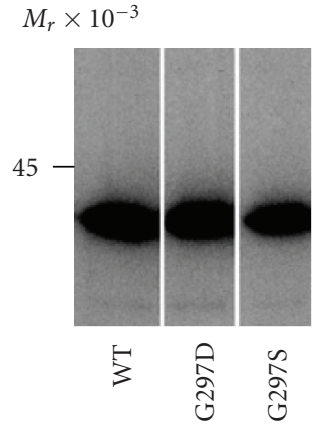

(ii)

(a)

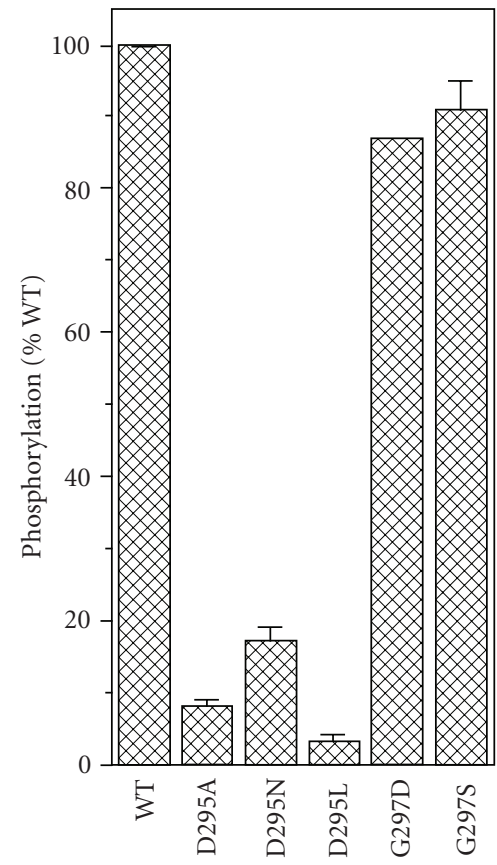

(b)

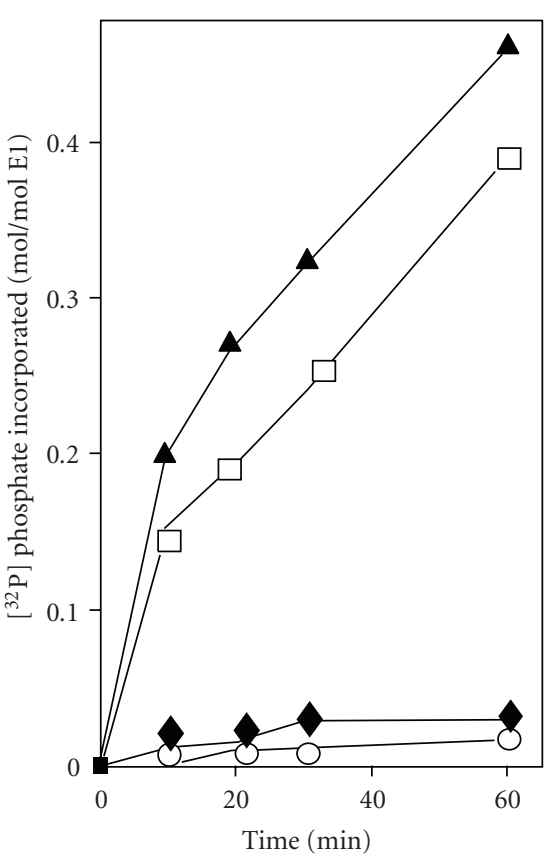

(c)

Figure 5: Phosphorylation of AtPDC E1 $\alpha$ active-site loop mutants by AtPDK. (a) (i) Autoradiograph comparing phosphorylation of WT AtPDC E1 and the Asp295 mutant. (a) (ii) Autoradiograph comparing phosphorylation of WT AtPDC E1 and the Gly297 mutant. One $\mu \mathrm{g}$ each of the WT and mutant proteins was incubated with $0.25 \mu \mathrm{g}$ AtPDK and $200 \mu \mathrm{M}\left[\gamma_{-}{ }^{32} \mathrm{P}\right] \mathrm{ATP}$ at $30^{\circ} \mathrm{C}$ for $90 \mathrm{~min}$. In each case the entire reaction mixture was loaded onto the gels. After electrophoresis, all gels were exposed to film for $3 \mathrm{~h}$. (b) Relative (to WT) phosphorylation of the Asp295 and Gly297 mutants is indicated. Data are mean values from at least three separate determinations \pm SEM. The value for $100 \%$ of WT phosphorylation was $0.7 \pm 0.02 \mu \mathrm{mol}^{32} \mathrm{P} \mu \mathrm{mol} \mathrm{AtPDC} \mathrm{E1} 1^{-1}$. (c) Time-course of phosphorylation. The WT AtPDC E1 ( $\mathbf{\Delta}$ ), and the G297D ( $\square$ ), D295A ( $\bigcirc$ ), and D295N ( $)$ mutant proteins, were phosphorylated as described in (a). Reactions volumes were $100 \mu \mathrm{L}$. Samples of $20 \mu \mathrm{L}$ were removed at each time point, mixed with SDS-sample buffer, heated, and then resolved by SDS-PAGE.

from potato mitochondria followed by MS analysis, which identified Ser292 as the only residue phosphorylated [49]. While phosphorylation of only site 1 was expected with the minimum in vitro system, multi-site phosphorylation remains a possibility upon addition of E2 or more likely as PDC.

Phosphorylation of Ser292 was affected considerably by changes to Asp295, being reduced in the order D295N < D295A < D295L (Figure 5(a)). Interaction between E1 $\alpha$ and PDK is a multistep process that involves recognition of the phosphorylation-site region, docking of the PDK with this region, and subsequent transfer of the phosphoryl group. It is unlikely that the major reduction in phosphorylation of these mutants was due to inhibition of PDK binding to $\mathrm{E} 1$, because there was no significant reduction of interaction between AtPDK and the D295N or D295A mutants (Figure 6). It is logical that the reduction in phosphorylation of the active-site loop mutants is due to disruption of the transfer of the $\gamma$-phosphate from ATP to E1 $\alpha$ Ser292, possibly the result in ordering or positioning of the active-site loop. 
Some protein Ser/Thr kinases have an affinity for amino acids with acidic, basic, or hydrophobic functional groups located at defined positions $\mathrm{N}$ - or C-terminal to the phosphorylation site [50]. Our results are similar to an earlier study employing synthetic peptides as substrates for PDK. In those studies, peptides with the D295N substitution were poorer substrates for bovine PDK [8]. The Asp295 residue is one of a group of charged residues that form an $\mathrm{H}$-bonding network that stabilizes the active-site loop [51], making it accessible to the lipoyl domain of E2. Perturbations in this network affect substrate channeling, and phosphorylation is believed to promote this disorder $[45,51]$. Based on the results from in silico mutagenesis, we hypothesize that interactions with His291 and Tyr300 would be disrupted if Asp295 were substituted (Figure 1(b)). Even substitution with Glu would be predicted to abolish the H-bond with His291, although we did not test this experimentally. The reduced phosphorylation seen with all changes to Asp295 is consistent with the proposal that altering the acidic residue C-terminal to Ser292 destabilizes the structure of the active-site loop. Alternatively, it is possible that conservation of Asp295 is part of a mechanism that maintains the active-site loop disordered and provides access to Ser292.

Changes to Asp295 have been reported to have pleiotropic effects on phosphorylation of E1. Phosphorylation of RnBCKDC E1 was not affected by mutagenesis of Asp295 [19], but was inhibited by mutagenesis of Arg288, which corresponds to Arg285 of AtPDC E1 $\alpha$. In contrast, the same mutations of HsBCKDC E1 did not inhibit phosphorylation [51]. The D296E mutant in HsPDC E1 $\alpha$ was still phosphorylated, although in these analyses the effect of phosphorylation was determined indirectly by measuring the decrease in activity of an already catalytically compromised mutant protein [52].

The catalytic response to the D295A change has been studied in other systems but using a similar assay method, which simplifies comparisons. In the case of AtPDC E1, the catalytic activities of the D295A and D295N mutants were reduced considerably (Table 1 ). The $K_{m}$ pyruvate values of these mutant proteins were increased 5-fold, while the $k_{\text {cat }}$ decreased by $>70 \%$. The response of the HsBCKDC E1 to the D295A mutation was essentially the same as with AtPDC E1 in terms of catalytic activity and $k_{\text {cat }}$ values; however, in that instance, the $K_{m}$ pyruvate was unaffected [51]. In a case of extreme contrasts, this D > A mutation of RnBCKDC E1 yielded a catalytically dead protein [19], while the activity of the B. stearothermophilus PDC E1 $\alpha$ actually increased 3 -fold (and the $K_{m}$ pyruvate value by 10 -fold) [18]. The modest but consistent reduction in $k_{\text {cat }}$ and $k_{\text {cat }} / K_{m}$ values seen with the AtPDC E1 mutants are in agreement with the proposal that Asp295 stabilizes the active-site loop conformation. The differences seen with ostensibly closely related enzymes suggest small or subtle differences in loop structure or stability. In the case of the more structurally distant E. coli PDC E1, the H-bonding loop-stabilizing pattern also involves nonconserved residues [53].

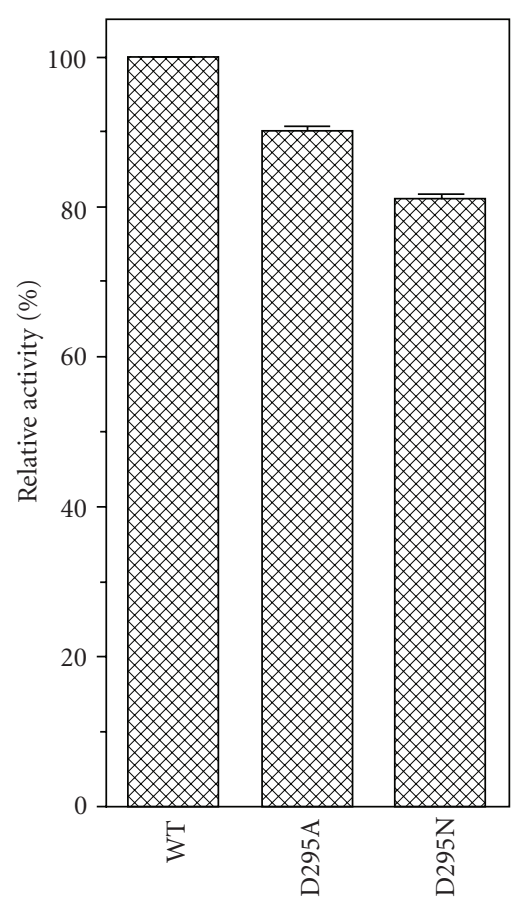

Figure 6: Quantitative analysis of interactions between AtPDC E1 and AtPDK. Quantitative B2H analysis was used to study interaction between WT AtPDC E1 $\alpha$, the D295A, and D295N mutants and AtPDK. The AtPDK sequence was cloned into the Stratagene $\mathrm{B} 2 \mathrm{H}$ vector $\mathrm{pBT}$, while the $\mathrm{E} 1 \alpha$ sequences were cloned into pTRG. After selection, protein interactions were quantified using the $\beta$-galactosidase reporter. The value for $100 \%$ of WT activity was $3 \mu \mathrm{mol} \mathrm{min}{ }^{-1} 1.0 \mathrm{~A} 600^{-1}$. Data are the mean \pm SEM from two separate experiments, each assay conducted in triplicate.

Binding of the TPP cofactor confers an ordering to the E1 $\alpha$ active-site loop. When the site 1 Ser residue is phosphorylated, the presence of the phosphoryl group prevents this ordering [53]. The mechanism involved has been referred to as a "steric clash" between the P-Ser at site 1 and a nearby Ser residue which then nullifies a hydrogenbonding network [45]. Some of the effects that we have seen with the AtPDC E1 $\alpha$ Asp295 mutants could be explained by this same mechanism. The disordered phosphorylation loops impede the binding of lipoyl domains of the PDC E2core to E1 [45]. The importance of structural order/disorder on protein phosphorylation is the subject of much current attention $[54,55]$.

The conserved Gly297 residue does not have an obvious role in the phosphorylation of the site 1 Ser residue. Phosphorylation was not affected in either the G297S mutant, where residue size is similar, or the G297D mutant which represents a drastic change (Figure 5(b)). These results seem to indicate that the residue present in this position is not directly involved with either formation or stabilization of the active-site loop structure. The reduction in $k_{\text {cat }}$, without any change in $K_{m}$ pyruvate, suggests that replacing Gly297 with a polar residue, such as Asp, might be interfering with interactions between Tyr-300 
and the carboxyl group of pyruvate, either directly or via steric hindrance.

Since all of the mutant subunits assembled into heterotetramers, neither Asp295 nor Gly297 is critical for subunit association. Moreover, the far-UV CD spectra of the mutant proteins were not distinguishable from the spectra obtained for the WT protein (data not presented), indicating that no gross structural perturbations occurred as a result of the mutations.

The defined in vitro system that we have developed is suitable for additional detailed analyses of the mechanism of regulatory phosphorylation of the plant mitochondrial PDC. Future studies will include the recombinant plant E2 proteins and domains and will address the differences in behavior between the mono- and dilipoyl forms of this core component of the PDC [56].

\section{Conflict of Interests}

The authors declare no conflict of interests.

\section{Abbreviations}

$\begin{array}{ll}\text { At: } & \begin{array}{l}\text { Arabidopsis thaliana } \\ \text { BCKDC: }\end{array} \\ & \begin{array}{l}\text { Branched-chain } \alpha \text {-ketoacid dehydrogenase } \\ \text { complex }\end{array} \\ \text { B2H: } & \text { Bacterial 2-hybrid } \\ \text { E1: } & \alpha \text {-ketoacid dehydrogenase/decarboxylase } \\ \text { E1 } \alpha: & \alpha \text {-subunit of E1 } \\ \text { Hs: } & \text { Homo sapiens } \\ \text { PDC: } & \text { Pyruvate dehydrogenase complex } \\ \text { PDK: } & \text { Pyruvate dehydrogenase-kinase } \\ \text { Rn: } & \text { Rattus norvegicus } \\ \text { WT: } & \text { Wild type. }\end{array}$

\section{Acknowledgments}

The authors thank Beverly Dague for the MS analyses, Anthony Gatenby for pGroESL, and Sayah Agah for assistance with the CD analysis. This research was supported by National Science Foundation Grant IBN-0325656, the Missouri Agricultural Experiment Station, and the Food for 21st Century Program.

\section{References}

[1] B. P. Mooney, J. A. Miernyk, and D. D. Randall, "The complex fate of $\alpha$-ketoacids," Annual Review of Plant Biology, vol. 53, pp. 357-375, 2002.

[2] A. Tovar-Méndez, J. A. Miernyk, and D. D. Randall, "Regulation of pyruvate dehydrogenase complex activity in plant cells," European Journal of Biochemistry, vol. 270, no. 6, pp. 1043-1049, 2003.

[3] S. Strumilo, "Short-term regulation of the $\alpha$-ketoglutarate dehydrogenase complex by energy-linked and some other effectors," Biochemistry, vol. 70, no. 7, pp. 726-729, 2005.

[4] M. S. Patel and L. G. Korotchkina, "Regulation of the pyruvate dehydrogenase complex," Biochemical Society Transactions, vol. 34, no. 2, pp. 217-222, 2006.
[5] D. T. Chuang, J. L. Chuang, and R. M. Wynn, "Lessons from genetic disorders of branched-chain amino acid metabolism," Journal of Nutrition, vol. 136, no. 1, pp. 243S-249S, 2006.

[6] M. C. Sugden and M. J. Holness, "Mechanisms underlying regulation of the expression and activities of the mammalian pyruvate dehydrogenase kinases," Archives of Physiology and Biochemistry, vol. 112, no. 3, pp. 139-149, 2006.

[7] T. E. Roche, J. C. Baker, X. Yan et al., "Distinct regulatory properties of pyruvate dehydrogenase kinase and phosphatase isoforms," Progress in Nucleic Acid Research and Molecular Biology, vol. 70, pp. 33-IN1, 2001.

[8] T. R. Mullinax, L. R. Stepp, J. R. Brown, and L. J. Reed, "Synthetic peptide substrates for mammalian pyruvate dehydrogenase kinase and pyruvate dehydrogenase phosphatase," Archives of Biochemistry and Biophysics, vol. 243, no. 2, pp. 655-659, 1985.

[9] G. E. Crooks, G. Hon, J. M. Chandonia, and S. E. Brenner, "WebLogo: a sequence logo generator," Genome Research, vol. 14, no. 6, pp. 1188-1190, 2004.

[10] K. Koike, Y. Urata, and S. Goto, "Proteinase-catalyzed activation of porcine heart muscle pyruvate dehydrogenase and identification of its cleavage site," Biochimica et Biophysica Acta, vol. 1118, no. 3, pp. 223-230, 1992.

[11] G. B. Kresze and H. Ronft, "Bovine kidney pyruvate dehydrogenase complex. Limited proteolysis and molecular structure of the lipoate acetyltransferase component," European Journal of Biochemistry, vol. 112, no. 3, pp. 589-599, 1980.

[12] G. B. Kresze, H. Ronft, B. Dietl, and L. Steber, "Limited proteolysis of 2-oxoglutarate dehydrogenase multienzyme complex from bovine kidney," FEBS Letters, vol. 127, no. 1, pp. 157-160, 1981.

[13] R. G. McCartney, J. E. Rice, S. J. Sanderson, V. Bunik, H. Lindsay, and J. G. Lindsay, "Subunit interactions in the mammalian $\alpha$-ketoglutarate dehydrogenase complex. Evidence for direct association of the $\alpha$-ketoglutarate dehydrogenase and dihydrolipoamide dehydrogenase components," Journal of Biological Chemistry, vol. 273, no. 37, pp. 24158-24164, 1998.

[14] H. J. Chauhan, G. J. Domingo, H. I. Jung, and R. N. Perham, "Sites of limited proteolysis in the pyruvate decarboxylase component of the pyruvate dehydrogenase multienzyme complex of Bacillus stearothermophilus and their role in catalysis," European Journal of Biochemistry, vol. 267, no. 24, pp. 71587169, 2000.

[15] A. Ævarsson, K. Seger, S. Turley, J. R. Sokatch, and W. G. J. Hol, "Crystal structure of 2-oxoisovalerate and dehydrogenase and the architecture of 2-oxo acid dehydrogenase multienzyme complexes," Nature Structural Biology, vol. 6, no. 8, pp. 785792, 1999.

[16] A. Ævarsson, J. L. Chuang, R. Max Wynn, S. Turley, D. T. Chuang, and W. G. J. Hol, "Crystal structure of human branched-chain $\alpha$-ketoacid dehydrogenase and the molecular basis of multienzyme complex deficiency in maple syrup urine disease," Structure, vol. 8, no. 3, pp. 277-291, 2000.

[17] L. Regad, J. Martin, G. Nuel, and A. C. Camproux, "Mining protein loops using a structural alphabet and statistical exceptionality," BMC Bioinformatics, vol. 11, article 75, 2010.

[18] M. Fries, H. J. Chauhan, G. J. Domingo, H. I. Jung, and R. N. Perham, "Site-directed mutagenesis of a loop at the active site of E1 $\left(\alpha_{2} \beta_{2}\right)$ of the pyruvate dehydrogenase complex: a possible common sequence motif," European Journal of Biochemistry, vol. 270, no. 5, pp. 861-870, 2003.

[19] J. W. Hawes, R. J. Schnepf, A. E. Jenkins, Y. Shimomura, K. M. Popov, and R. A. Harris, "Roles of amino acid 
residues surrounding phosphorylation site 1 of branchedchain $\alpha$-ketoacid dehydrogenase (BCKDH) in catalysis and phosphorylation site recognition by BCKDH kinase," Journal of Biological Chemistry, vol. 270, no. 52, pp. 31071-31076, 1995.

[20] R. M. Wynn, M. Machius, J. L. Chuang, J. Li, D. R. Tomchick, and D. T. Chuang, "Roles of $\mathrm{His}^{291}-\alpha$ and his ${ }^{146}-\beta^{\prime}$ in the reductive acylation reaction catalyzed by human branchedchain $\alpha$-ketoacid dehydrogenase: refined phosphorylation loop structure in the active site," Journal of Biological Chemistry, vol. 278, no. 44, pp. 43402-43410, 2003.

[21] H. H. M. Dahl, L. L. Hansen, R. M. Brown, D. M. Danks, J. G. Rogers, and G. K. Brown, "X-Linked pyruvate dehydrogenase E1 $\alpha$ subunit deficiency in heterozygous females: variable manifestation of the same mutation," Journal of Inherited Metabolic Disease, vol. 15, no. 6, pp. 835-847, 1992.

[22] K. Chun, N. Mackay, R. Petrova-Benedict, and B. H. Robinson, "Mutations in the X-linked E1 $\alpha$ subunit of pyruvate dehydrogenase leading to deficiency of the pyruvate dehydrogenase complex," Human Molecular Genetics, vol. 2, no. 4, pp. 449$454,1993$.

[23] J. I. Moreno, J. A. Miernyk, and D. D. Randall, "Staphylococcal protein A as a fusion partner directs secretion of the E1 $\alpha$ and E1 $\beta$ subunits of pea mitochondrial pyruvate dehydrogenase by Bacillus subtilis," Protein Expression and Purification, vol. 18, no. 2, pp. 242-248, 2000.

[24] J. I. Moreno, N. R. David, J. A. Miernyk, and D. D. Randall, "Pisum sativum mitochondrial pyruvate dehydrogenase can be assembled as a functional $\alpha \beta$ heterotetramer in the cytoplasm of Pichia pastoris," Protein Expression and Purification, vol. 19, no. 2, pp. 276-283, 2000.

[25] M. H. Luethy, J. A. Miernyk, and D. D. Randall, "The mitochondrial pyruvate dehydrogenase complex: nucleotide and deduced amino-acid sequences of a cDNA encoding the Arabidopsis thaliana E1 $\alpha$-subunit," Gene, vol. 164, no. 2, pp. 251-254, 1995.

[26] S. Tabor and C. C. Richardson, "A bacteriophage T7 RNA polymerase/promoter system for controlled exclusive expression of specific genes," Proceedings of the National Academy of Sciences of the United States of America, vol. 82, no. 4, pp. 10741078, 1985.

[27] M. H. Luethy, J. A. Miernyk, and D. D. Randall, "The nucleotide and deduced amino acid sequences of a cDNA encoding the E1 $\beta$-subunit of the Arabidopsis thaliana mitochondrial pyruvate dehydrogenase complex," Biochimica et Biophysica Acta, vol. 1187, no. 1, pp. 95-98, 1994.

[28] A. Einhauer and A. Jungbauer, "The FLAG peptide, a versatile fusion tag for the purification of recombinant proteins," Journal of Biochemical and Biophysical Methods, vol. 49, no. 13, pp. 455-465, 2001.

[29] C. E. Kalbach and A. A. Gatenby, "Stable expression plasmid for high-level production of GroE molecular chaperones in large-scale cultures," Enzyme and Microbial Technology, vol. 15, no. 9, pp. 730-735, 1993.

[30] A. Tovar-Méndez, T. A. Hirani, J. A. Miernyk, and D. D. Randall, "Analysis of the catalytic mechanism of pyruvate dehydrogenase kinase," Archives of Biochemistry and Biophysics, vol. 434, no. 1, pp. 159-168, 2005.

[31] J. J. Thelen, J. A. Miernyk, and D. D. Randall, "Partial purification and characterization of the maize mitochondrial pyruvate dehydrogenase complex," Plant Physiology, vol. 116, no. 4, pp. 1443-1450, 1998.
[32] M. H. Luethy, N. R. David, T. E. Elthon, J. A. Miernyk, and D. D. Randall, "Characterization of a monoclonal antibody recognizing the E1 $\alpha$ subunit of plant mitochondrial pyruvate dehydrogenase," Journal of Plant Physiology, vol. 145, no. 4, pp. 443-449, 1995.

[33] K. Biemann, "Nomenclature for peptide fragment ions (positive ions)," Methods in Enzymology, vol. 193, pp. 886-887, 1990.

[34] G. B. Kresze, "An improved procedure for the assay of pyruvate dehydrogenase," Analytical Biochemistry, vol. 98, no. 1, pp. 85$88,1979$.

[35] K. L. Griffith and R. E. Wolf, "Measuring $\beta$-galactosidase activity in bacteria: cell growth, permeabilization, and enzyme assays in 96-well arrays," Biochemical and Biophysical Research Communications, vol. 290, no. 1, pp. 397-402, 2002.

[36] Y. Suo and J. A. Miernyk, "Regulation of nucleocytoplasmic localization of the atDjC6 chaperone protein," Protoplasma, vol. 224, no. 1-2, pp. 79-89, 2004.

[37] M. L. Johnston, J. A. Miernyk, and D. D. Randall, "Import, processing, and assembly of the $\alpha$ - and $\beta$-subunits of chloroplast pyruvate dehydrogenase," Planta, vol. 211, no. 1, pp. 7276, 2000.

[38] B. Szurmak, L. Strokovskaya, B. P. Mooney, D. D. Randall, and J. A. Miernyk, "Expression and assembly of Arabidopsis thaliana pyruvate dehydrogenase in insect cell cytoplasm," Protein Expression and Purification, vol. 28, no. 2, pp. 357-361, 2003.

[39] S. Witzmann and H. Bisswanger, "The pyruvate dehydrogenase complex from thermophilic organisms: thermal stability and re-association from the enzyme components," Biochimica et Biophysica Acta, vol. 1385, no. 2, pp. 341-352, 1998.

[40] J. L. Chuang, R. M. Wynn, J. L. Song, and D. T. Chuang, "GroEL/GroES-dependent reconstitution of $\alpha_{2} \beta_{2}$ tetramers of human mitochondrial branched chain $\alpha$-ketoacid decarboxylase: obligatory interaction of chaperonins with an $\alpha \beta$ dimeric intermediate," Journal of Biological Chemistry, vol. 274, no. 15, pp. 10395-10404, 1999.

[41] R. M. Wynn, J. L. Song, and D. T. Chuang, "GroEL/GroES promote dissociation/reassociation cycles of a heterodimeric intermediate during $\alpha_{2} \beta_{2}$ protein assembly: iterative annealing at the quaternary structure level," Journal of Biological Chemistry, vol. 275, no. 4, pp. 2786-2794, 2000.

[42] L. G. Korotchkina and M. S. Patel, "Probing the mechanism of inactivation of human pyruvate dehydrogenase by phosphorylation of three sites," Journal of Biological Chemistry, vol. 276, no. 8, pp. 5731-5738, 2001.

[43] E. R. Schwartz and L. J. Reed, "Regulation of the activity of the pyruvate dehydrogenase complex of escherichia coif," Biochemistry, vol. 9, no. 6, pp. 1434-1439, 1970.

[44] J. A. Miernyk and D. D. Randall, "Some kinetic and regulatory properties of the pea mitochondrial pyruvate dehydrogenase," Plant Physiology, vol. 83, pp. 306-310, 1987.

[45] M. Kato, R. M. Wynn, J. L. Chuang et al., "Structural basis for inactivation of the human pyruvate dehydrogenase complex by phosphorylation: role of disordered phosphorylation loops," Structure, vol. 16, no. 12, pp. 1849-1859, 2008.

[46] L. G. Korotchkina and M. S. Patel, "Mutagenesis studies of the phosphorylation sites of recombinant human pyruvate dehydrogenase. Site-specific regulation," Journal of Biological Chemistry, vol. 270, no. 24, pp. 14297-14304, 1995.

[47] D. Yang, X. Gong, A. Yakhnin, and T. E. Roche, "Requirements for the adaptor protein role of dihydrolipoyl acetyltransferase in the up-regulated function of the pyruvate dehydrogenase 
kinase and pyruvate dehydrogenase phosphatase," Journal of Biological Chemistry, vol. 273, no. 23, pp. 14130-14137, 1998.

[48] H. Bao, S. A. Kasten, X. Yan, Y. Hiromasa, and T. E. Roche, "Pyruvate dehydrogenase kinase isoform 2 activity stimulated by speeding up the rate of dissociation of ADP," Biochemistry, vol. 43, no. 42, pp. 13442-13451, 2004.

[49] N. V. Bykova, A. Stensballe, H. Egsgaard, O. N. Jensen, and I. M. Møller, "Phosphorylation of formate dehydrogenase in potato tuber mitochondria," Journal of Biological Chemistry, vol. 278, no. 28, pp. 26021-26030, 2003.

[50] R. B. Pearson and B. E. Kemp, "Protein kinase phosphorylation site sequences and consensus specificity motifs: tabulations," Methods in Enzymology, vol. 200, pp. 62-81, 1991.

[51] J. Li, R. M. Wynn, M. Machius et al., "Cross-talk between thiamin diphosphate binding and phosphorylation loop conformation in human branched-chain $\alpha$-keto acid decarboxylase/dehydrogenase," Journal of Biological Chemistry, vol. 279, no. 31, pp. 32968-32978, 2004.

[52] R. M. Brown, R. A. Head, I. I. Boubriak, J. V. Leonard, and G. K. Brown, "A pathogenic glutamate-to-aspartate substitution (D296E) in the pyruvate dehydrogenase E1 subunit gene PDHA1," Human Mutation, vol. 22, pp. 496-497, 2003.

[53] P. Arjunan, K. Chandrasekhar, M. Sax et al., "Structural determinants of enzyme binding affinity: the E1 component of pyruvate dehydrogenase from Escherichia coli in complex with the inhibitor thiamin thiazolone diphosphate," Biochemistry, vol. 43, no. 9, pp. 2405-2411, 2004.

[54] L. M. Iakoucheva, P. Radivojac, C. J. Brown et al., "The importance of intrinsic disorder for protein phosphorylation," Nucleic Acids Research, vol. 32, no. 3, pp. 1037-1049, 2004.

[55] J. Gao, G. K. Agrawal, J. J. Thelen, Z. Obradovic, A. K. Dunker, and $\mathrm{D} . \mathrm{Xu}$, "A new machine learning approach for protein phosphorylation site prediction in plants," in Proceedings of the 1st International Conference on Bioinformatics and Computational Biology, vol. 5462 of Lecture Notes in Computer Science, pp. 18-29, New Orleans, La, USA, 2009.

[56] J. J. Thelen, M. G. Muszynski, N. R. David et al., "The dihydrolipoamide S-acetyltransferase subunit of the mitochondrial pyruvate dehydrogenase complex from maize contains a single lipoyl domain," Journal of Biological Chemistry, vol. 274, no. 31, pp. 21769-21775, 1999. 

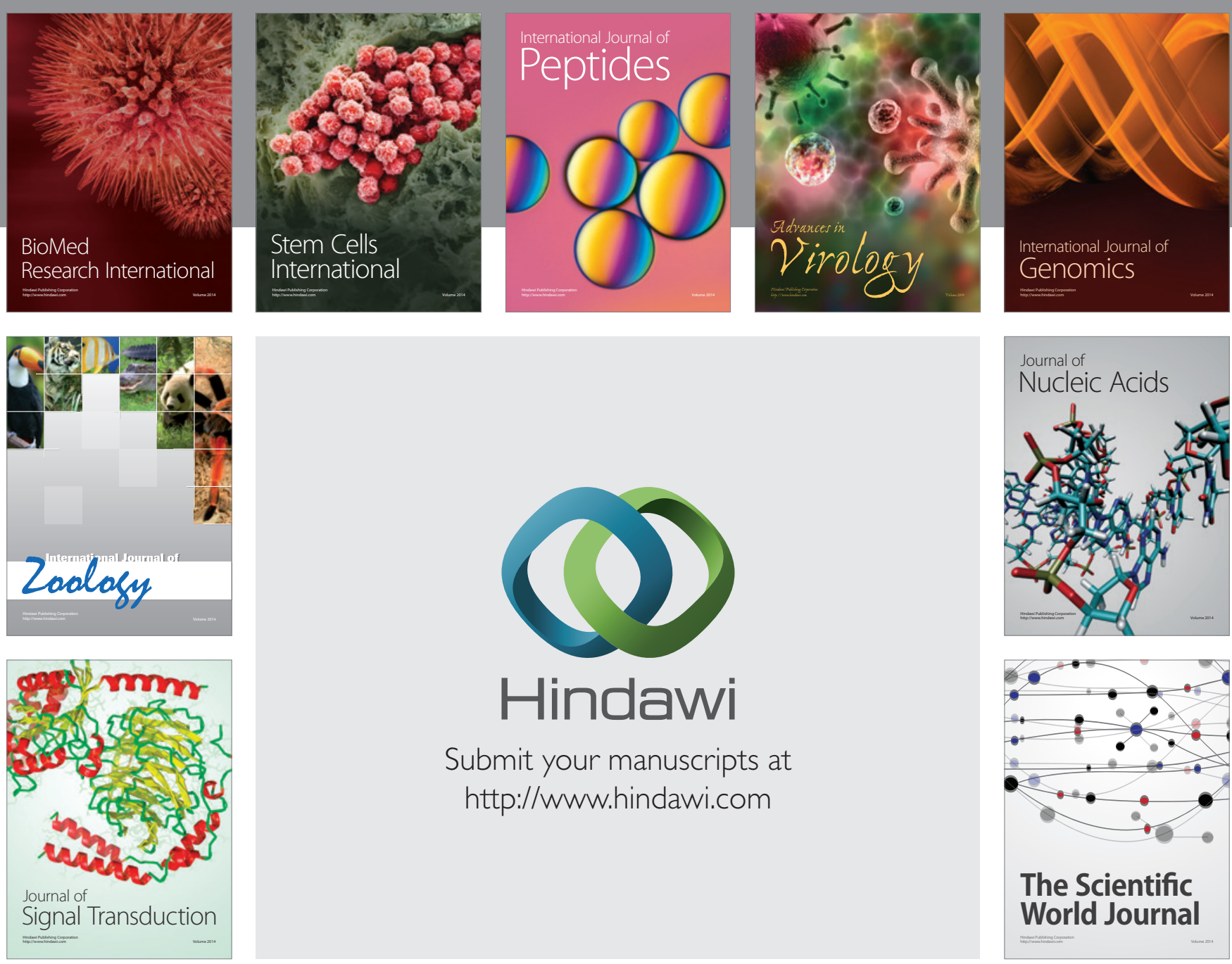

Submit your manuscripts at

http://www.hindawi.com
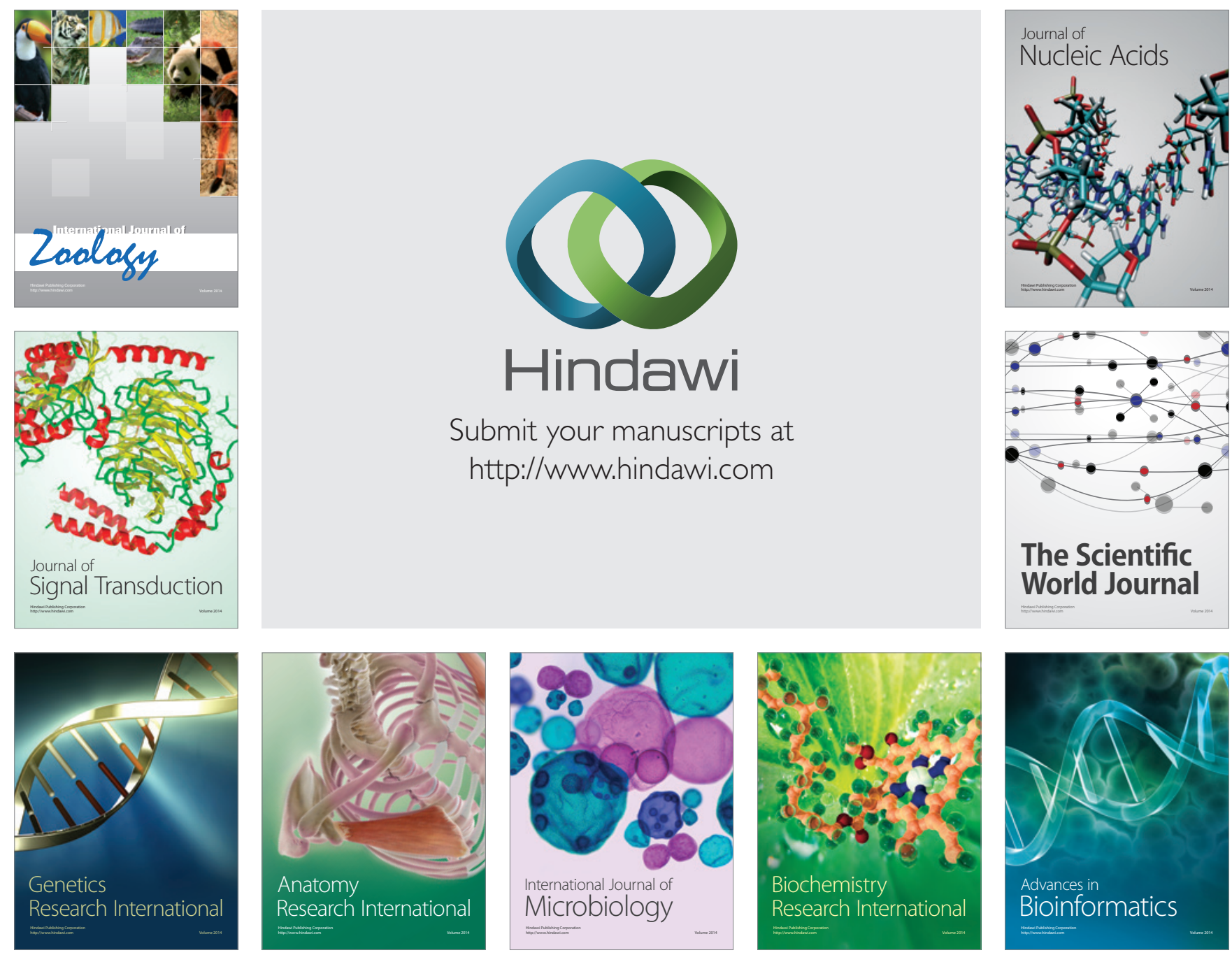

The Scientific World Journal
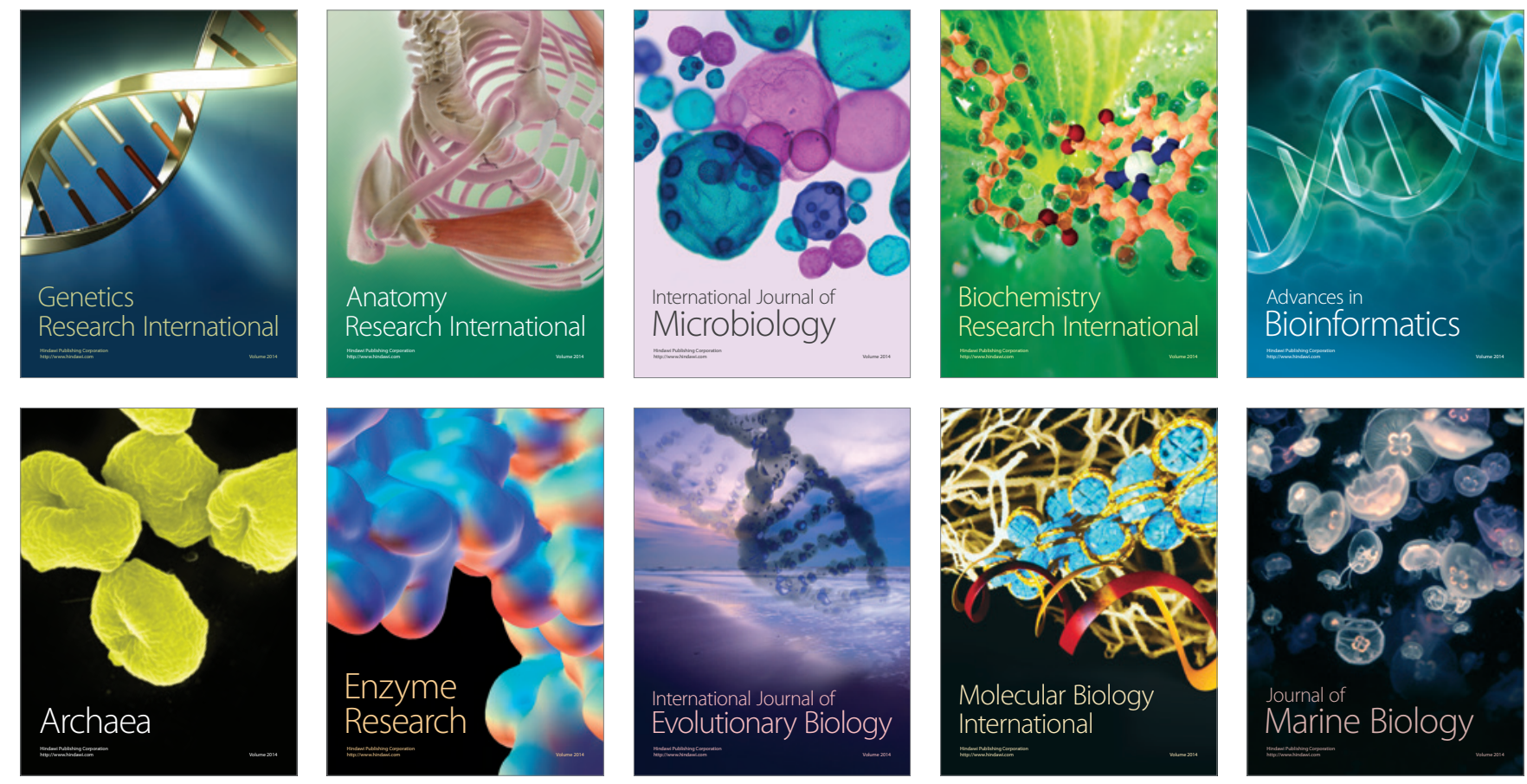